\title{
Non contiguous-finished genome sequence and descrip- tion of Enterobacter massiliensis sp. nov.
}

\author{
Jean-Christophe Lagier ${ }^{1}$, Khalid El Karkouri ${ }^{1}$, Ajay Kumar Mishra ${ }^{1}$, Catherine Robert ${ }^{1}$, Didier \\ Raoult $^{1}$ and Pierre-Edouard Fournier ${ }^{1 *}$ \\ ${ }^{1}$ Aix-Marseille Université, Faculté de médecine, Marseille, France \\ *Corresponding author: Pierre-Edouard Fournier (pierre-edouard.fournier@univmed.fr)
}

Keywords: Enterobacter massiliensis, genome

Enterobacter massiliensis strain JC163 ${ }^{\top}$ sp. nov. is the type strain of E. massiliensis sp. nov., a new species within the genus Enterobacter. This strain, whose genome is described here, was isolated from the fecal flora of a healthy Senegalese patient. E. massiliensis is an aerobic rod. Here we describe the features of this organism, together with the complete genome sequence and annotation. The 4,922,247 bp long genome ( 1 chromosome but no plasmid) exhibits a $\mathrm{G}+\mathrm{C}$ content of $55.1 \%$ and contains 4,644 protein-coding and 80 RNA genes, including 5 rRNA genes.

\section{Introduction}

Enterobacter massiliensis strain JC163 ${ }^{\mathrm{T}}$ (= CSUR $\mathrm{P} 161=$ DSM 26120) is the type strain of $E$. massiliensis sp. nov. This bacterium is a Gramnegative, aerobic, flagellate, indole-positive bacillus that was isolated from the feces of a healthy Senegalese patient in a study aiming at cultivating all bacterial species in human feces [1]. The current classification of prokaryotes, known as polyphasic taxonomy, relies on a combination of phenotypic and genotypic characteristics [2]. However, as more than 3,000 bacterial genomes have been sequenced [3] and the cost of genomic sequencing is decreasing, we recently proposed to integrate genomic information in the description of new bacterial species [4-15].

Here we present a summary classification and a set of features for E. massiliensis sp. nov. strain JC163 ${ }^{\mathrm{T}}$ (= CSUR P161 = DSM 26120), together with the description of the complete genomic sequencing and annotation. These characteristics support the circumscription of the species $E$. massiliensis. The genus Enterobacter (Hormaeche and Edwards, 1960) was created in 1960 [16]. To date, this genus is comprised of 25 species [17-35] and 2 subspecies. Members of the genus were isolated mostly from the environment, in particular from plants and fruits, but are also frequently isolated from humans, notably in health-care associated infections, causing bacteremia, pneumonia or urinary tract infections [36]. In addition, many
Enterobacter spp. were isolated from the normal fecal flora.

\section{Classification and features}

A stool sample was collected from a healthy 16year-old male Senegalese volunteer patient living in Dielmo (rural village in the Guinean-Sudanian zone in Senegal), who was included in a research protocol. Written assent was obtained from this individual. No written consent was needed from his guardians for this study because he was older than 15 years old (in accordance with the previous project approved by the Ministry of Health of Senegal and the assembled village population and as published elsewhere [37]).

Both this study and the assent procedure were approved by the National Ethics Committee of Senegal (CNERS) and the Ethics Committee of the Institut Fédératif de Recherche IFR48, Faculty of Medicine, Marseille, France (agreement numbers 09-022 and 11-017). Several other new bacterial species were isolated from this specimen using various culture conditions, including the recently described Alistipes senegalensis, Alistipes timonensis, Anaerococcus senegalensis, Bacillus timonensis, Clostridium senegalense, Peptoniphilus timonensis, Paenibacillus senegalensis, Herbaspirillum massiliense, Kurthia massiliensis, 
Brevibacterium senegalense, Aeromicrobium massiliense and Cellulomonas massiliensis [4-15].

The fecal specimen was preserved at $-80^{\circ} \mathrm{C}$ after collection and sent to Marseille. Strain JC163 (Table 1) was isolated in April 2011 by aerobic cultivation on Brain-Heart Infusion (BHI) agar at $37^{\circ} \mathrm{C}$ after preincubation of the stool specimen with lytic E. coli T1 and T4 phages [1,50]. This strain exhibited a nucleotide sequence similarity with Enterobacter species ranging from 95.74\% with E. pyrinus (Chung et al., 1993) to $97.33 \%$ with E. cloacae subsp. cloacae (Jordan, 1980) (Figure 1). This latter value was lower than the $98.7 \%$ $16 \mathrm{~S}$ rRNA gene sequence threshold recommended by Stackebrandt and Ebers to delineate a new species without carrying out DNA-DNA hybridization [51].

Table 1. Classification and general features of Enterobacter massiliensis strain JC163 ${ }^{\top}$

\begin{tabular}{|c|c|c|c|}
\hline MIGS ID & Property & Term & Evidence code $^{a}$ \\
\hline & \multirow{8}{*}{ Current classification } & Domain: Bacteria & TAS [38] \\
\hline & & Phylum Proteobacteria & TAS [39] \\
\hline & & Class Gammaproteobacteria & TAS $[40,41]$ \\
\hline & & Order "Enterobacteriales" & TAS [42] \\
\hline & & Family Enterobacteriaceae & TAS [43-45] \\
\hline & & Genus Enterobacter & TAS $[16,44,46-48]$ \\
\hline & & Species Enterobacter massiliensis & IDA \\
\hline & & Type strain: JC163 ${ }^{\top}$ & IDA \\
\hline & Gram stain & Negative & IDA \\
\hline & Cell shape & Rod & IDA \\
\hline & Motility & Motile & IDA \\
\hline & Sporulation & Nonsporulating & IDA \\
\hline & Temperature range & Mesophile & IDA \\
\hline & Optimum temperature & $37^{\circ} \mathrm{C}$ & IDA \\
\hline MIGS-6.3 & Salinity & Unknown & IDA \\
\hline \multirow[t]{3}{*}{ MIGS-22 } & Oxygen requirement & Aerobic & IDA \\
\hline & Carbon source & Unknown & NAS \\
\hline & Energy source & Unknown & NAS \\
\hline MIGS-6 & Habitat & Human gut & IDA \\
\hline \multirow[t]{3}{*}{ MIGS-15 } & Biotic relationship & Free living & IDA \\
\hline & Pathogenicity & Unknown & \\
\hline & Biosafety level & 2 & \\
\hline MIGS-14 & Isolation & Human feces & \\
\hline MIGS-4 & Geographic location & Senegal & IDA \\
\hline MIGS-5 & Sample collection time & September 2010 & IDA \\
\hline MIGS-4.1 & Latitude & 13.7167 & IDA \\
\hline MIGS-4.1 & Longitude & -16.4167 & IDA \\
\hline MIGS-4.3 & Depth & Surface & IDA \\
\hline MIGS-4.4 & Altitude & $51 \mathrm{~m}$ above sea level & IDA \\
\hline
\end{tabular}

Evidence codes - IDA: Inferred from Direct Assay; TAS: Traceable Author Statement (i.e., a direct report exists in the literature); NAS: Non-traceable Author Statement (i.e., not directly observed for the living, isolated sample, but based on a generally accepted property for the species, or anecdotal evidence). These evidence codes are from the Gene Ontology project [49]. If the evidence is IDA, then the property was directly observed for a live isolate by one of the authors or an expert mentioned in the acknowledgements. 


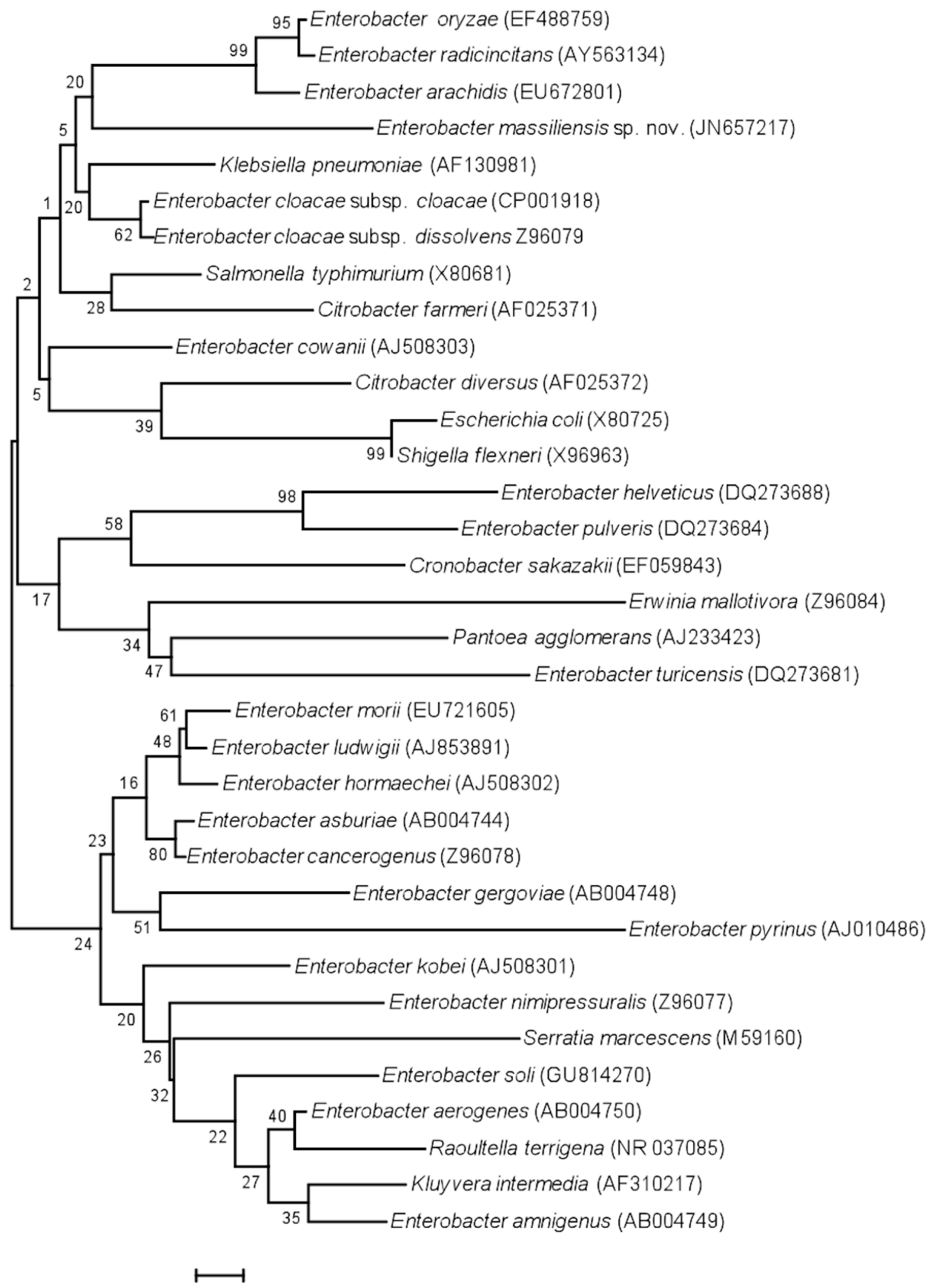

Figure 1. Phylogenetic tree highlighting the position of Enterobacter massiliensis strain JC163 relative to other type strains within the Enterobacter genus. Members of phylogenetically closely related genera were also included. GenBank accession numbers are indicated in parentheses. Sequences were aligned using CLUSTALW, and phylogenetic inferences obtained using the maximum-likelihood method within the MEGA software. Numbers at the nodes are percentages of bootstrap values obtained by repeating the analysis 500 times to generate a majority consensus tree. The scale bar represents a $0.2 \%$ nucleotide sequence divergence. 


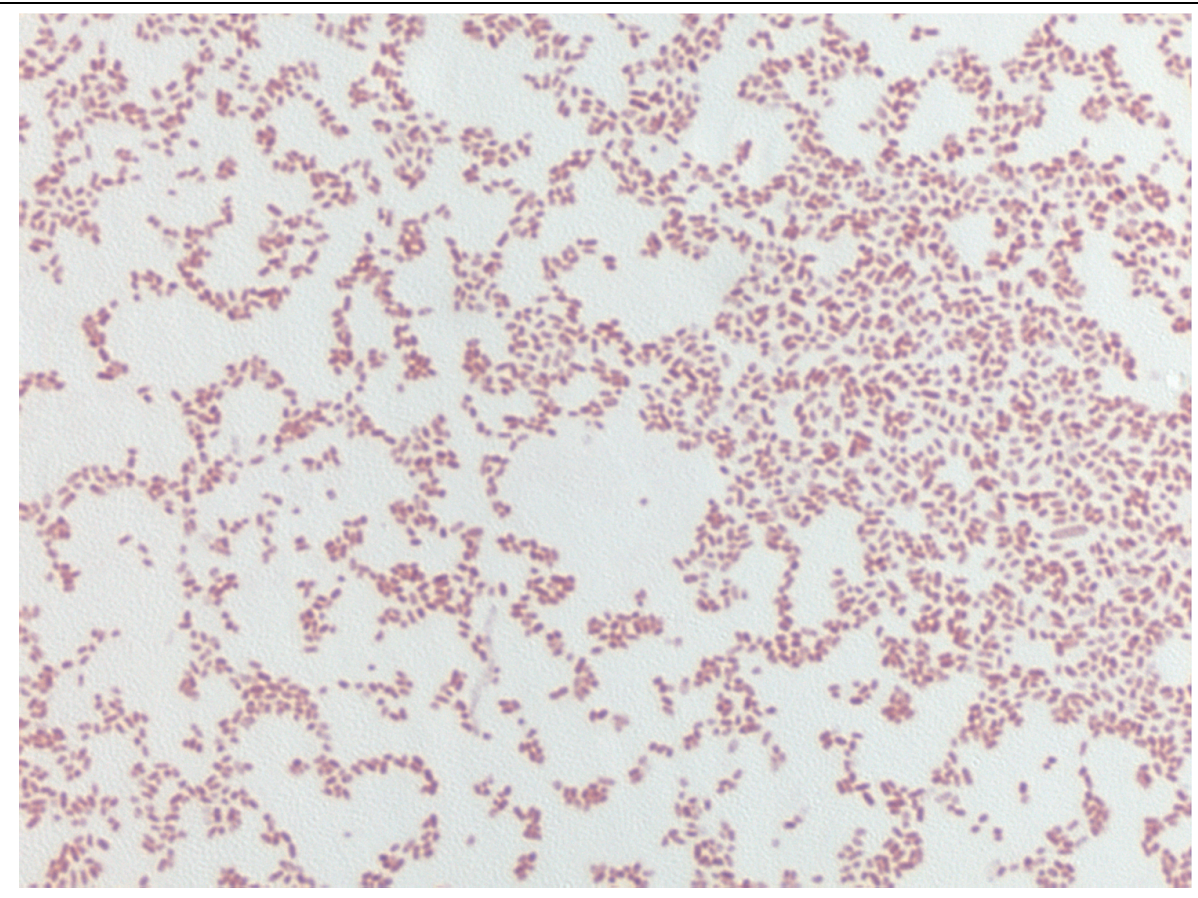

Figure 2. Gram staining of E. massiliensis strain JC163

Different growth temperatures $\left(25,30,37,45^{\circ} \mathrm{C}\right)$ were tested; growth occurred between 25 and $45^{\circ} \mathrm{C}$, optimal growth was observed between 30 and $37^{\circ} \mathrm{C}$. Colonies were convex, opaque, light-cream colored and circular with regular margins and with a diameter of $2 \mathrm{~mm}$ on BHI agar. Growth of the strain was tested under anaerobic and microaerophilic conditions using GENbag anaer and GENbag microaer systems, respectively (BioMerieux), and under aerobic conditions, with or without $5 \% \mathrm{CO}_{2}$. Optimal growth was obtained under aerobic conditions in the presence of $5 \% \mathrm{CO}_{2}$. Weak growth was observed under microaerophilic condition. No growth was obtained anaerobically. A motility test was positive. Cells grown on agar are Gram-negative rods (Figure 2) and have a mean diameter of $1.02 \mu \mathrm{m}$ and a mean length of $1.90 \mu \mathrm{m}$ and have several polar flagella (Figure 3).

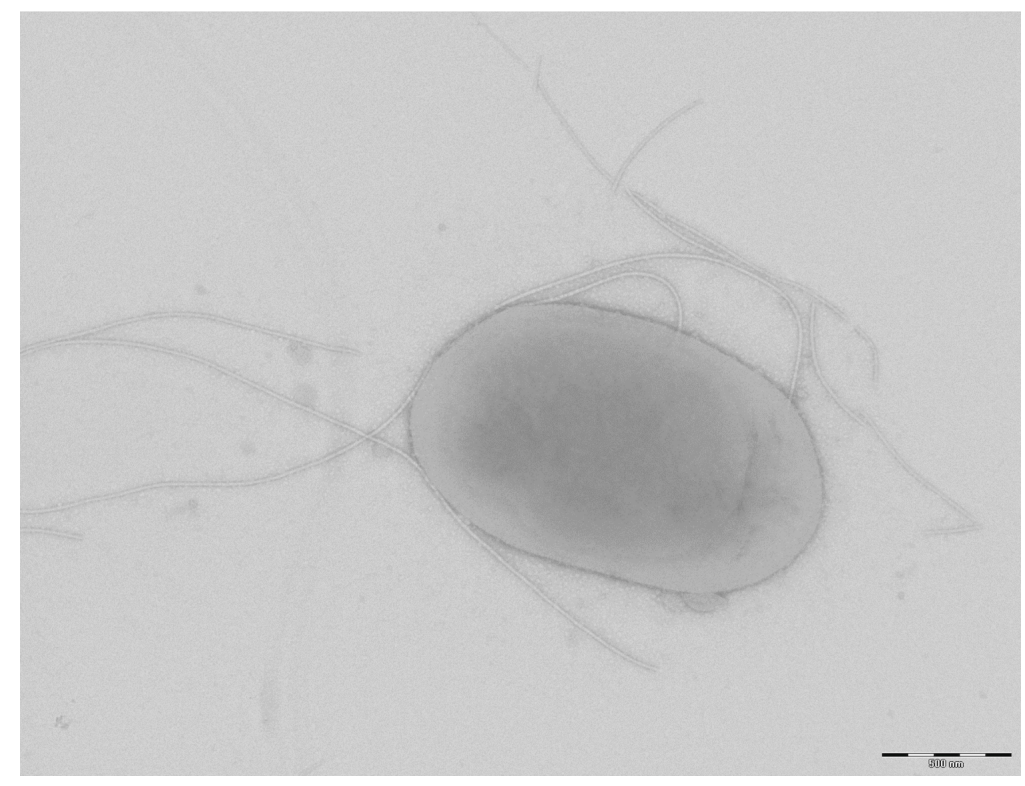

Figure 3. Transmission electron microscopy of E. massiliensis strain $\mathrm{JC} 163^{\top}$, using a Morgani 268D (Philips) at an operating voltage of $60 \mathrm{kV}$. The scale bar represents $500 \mathrm{~nm}$. 
Strain JC163 ${ }^{\mathrm{T}}$ exhibited catalase activity but not oxidase activity. Using the API 20E system, positive reactions were obtained for indole production, $\beta$-galactosidase and glucose, mannitol, sorbitol and rhamnose fermentation. E. massiliensis is susceptible to ticarcillin, imipenem, trimethoprim/sulfamthoxazole, gentamicin, amikacin, and colimycin but resistant to fosfomycin and nitrofurantoin. By comparison with E. arachidis, its phylogenetically-closest neighbor, $E$. massiliensis differed in arginine dihydrolase, ornithine decarboxylase, citrate and succinate fermentation [19].

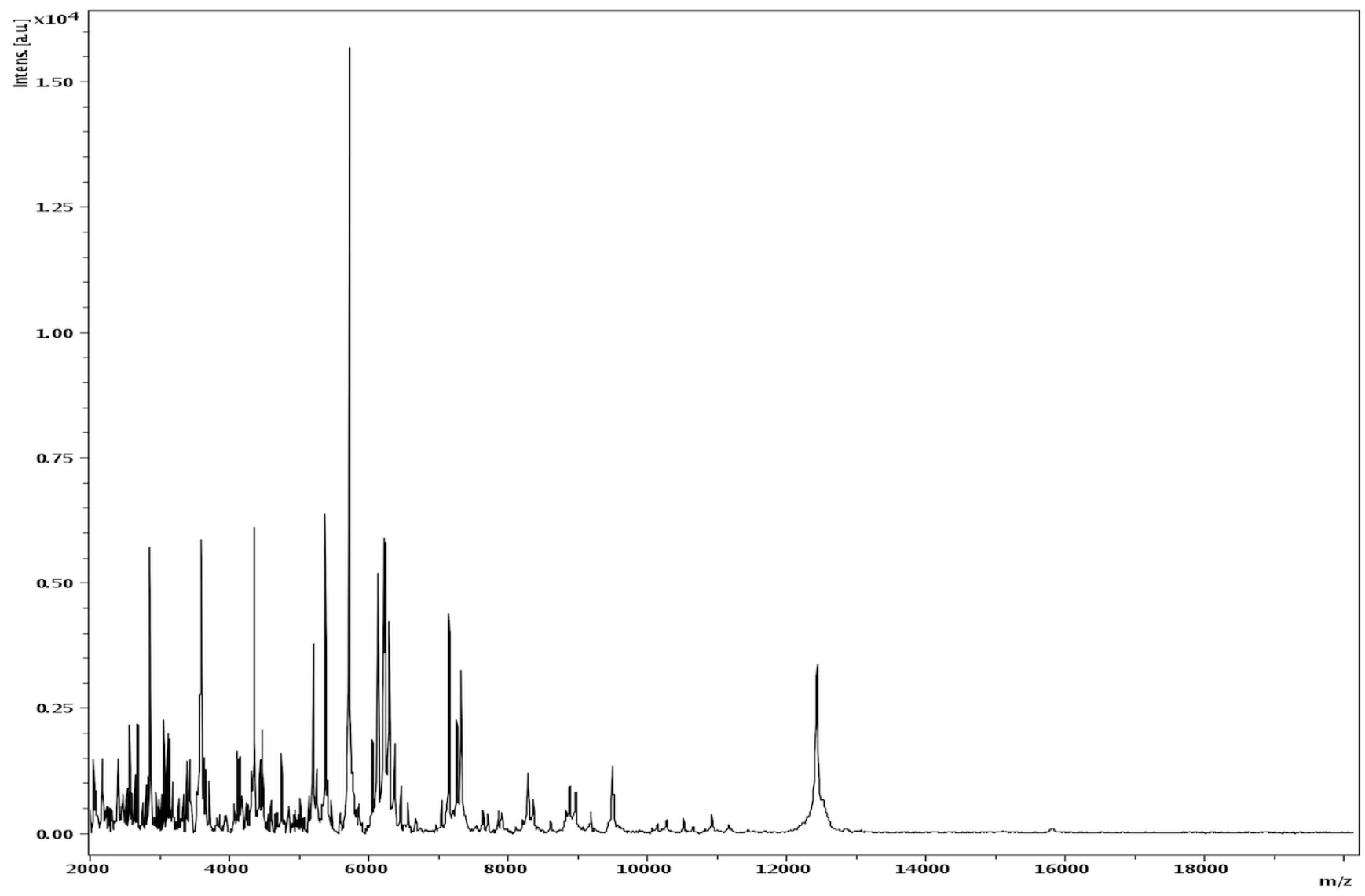

Figure 4. Reference mass spectrum from E. massiliensis strain JC163T. Spectra from 12 individual colonies were compared and a reference spectrum was generated.

Matrix-assisted laser-desorption/ionization timeof-flight (MALDI-TOF) MS protein analysis was carried out as previously described [52]. Briefly, a pipette tip was used to pick one isolated bacterial colony from a culture agar plate and spread it as a thin film on a MTP 384 MALDI-TOF target plate (Bruker Daltonics, Germany). Twelve distinct deposits were done for strain JC163 ${ }^{\mathrm{T}}$ from twelve isolated colonies. Each smear was overlaid with $2 \mu \mathrm{L}$ of matrix solution (saturated solution of alphacyano-4-hydroxycinnamic acid) in 50\% acetonitrile, $2.5 \%$ tri-fluoracetic acid, and allowed to dry for five minutes. Measurements were performed with a Microflex spectrometer (Bruker). Spectra were recorded in the positive linear mode for the mass range of 2,000 to 20,000 Da (parameter settings: ion source 1 (ISI), 20kV; IS2, $18.5 \mathrm{kV}$; lens, 7 $\mathrm{kV}$ ). A spectrum was obtained after 675 shots at a variable laser power. The time of acquisition was between 30 seconds and 1 minute per spot. The twelve $\mathrm{JC} 163^{\mathrm{T}}$ spectra were imported into the MALDI BioTyper software (version 2.0, Bruker) and analyzed by standard pattern matching (with default parameter settings) against the main spectra of 3,769 bacteria, including spectra from 34 spectra from validly published Enterobacter species that were used as reference data in the BioTyper database (updated March 15th 2012). The method of identification includes the $\mathrm{m} / \mathrm{z}$ from 3,000 to $15,000 \mathrm{Da}$. For every spectrum, a maximum of 100 
peaks were taken into account and compared with the spectra in database. A score enabled the presumptive identification and discrimination of the tested species from those in a database: a score $\geq 2$ with a validly published species enabled the identification at the species level; a score $\geq 1.7$ but $<2$ enabled the identification at the genus level; and a score $<1.7$ did not enable any identification. For strain JC163', the score obtained was 1.4 , suggesting that our isolate was not a member of a known species. We incremented our database with the spectrum from strain JC163 ${ }^{\mathrm{T}}$ (Figure 4). In addition, the gel view allows the highlighting of spectra differences with other of Enterobacteriaceae family members (Figure 5).

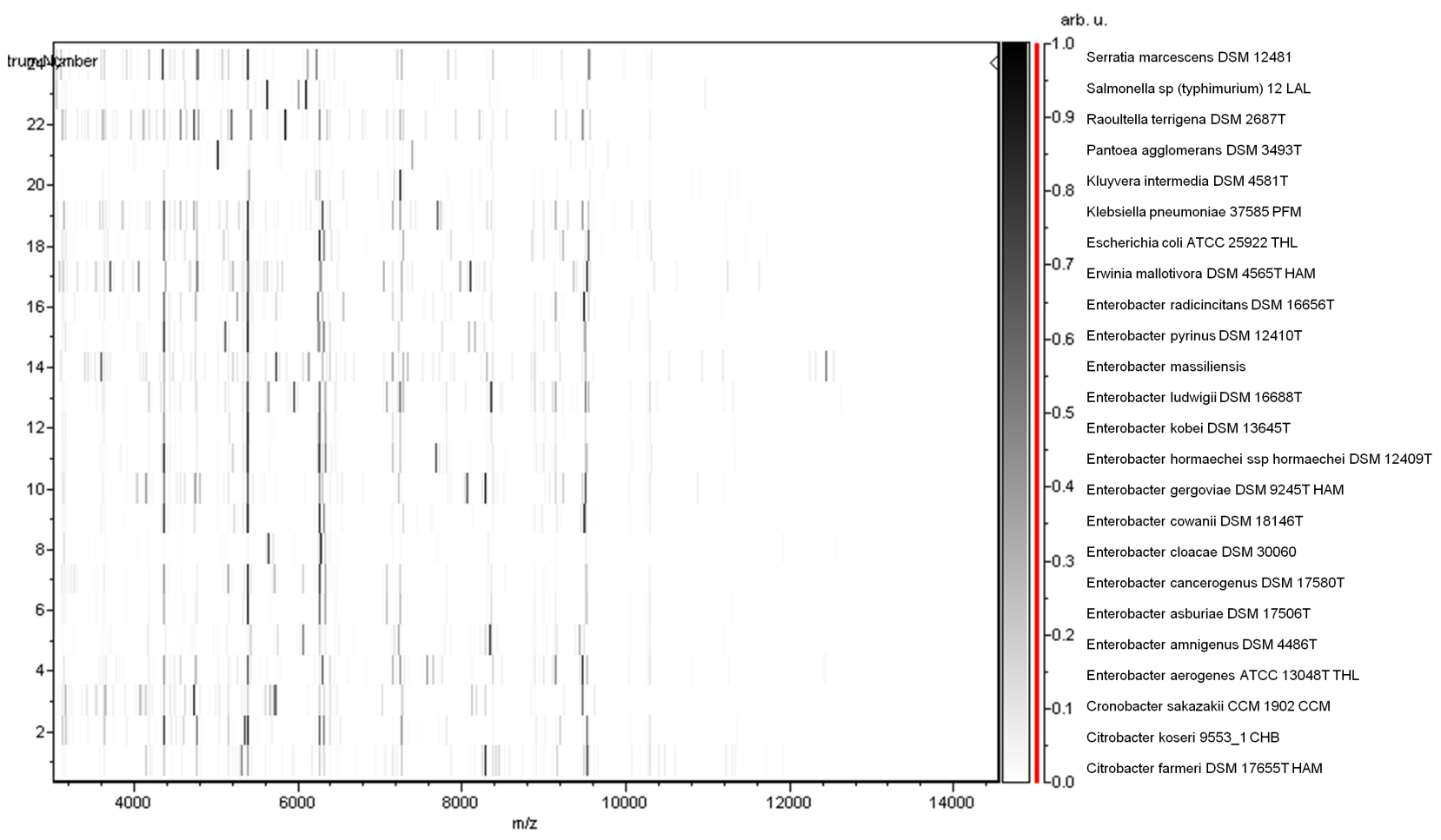

Figure 5. Gel view comparing Enterobacter massiliensis JC163 spectra with 23 other members into Enterobacteriaceae family. The Gel View displays the raw spectra of all loaded spectrum files arranged in a pseudo-gel like look. The $x-$ axis records the $\mathrm{m} / \mathrm{z}$ value. The left $\mathrm{y}$-axis displays the running spectrum number originating from subsequent spectra loading. The peak intensity is expressed by a Gray scale scheme code. The color bar and the right $y$-axis indicate the relation between the color a peak is displayed with and the peak intensity in arbitrary units.

\section{Genome sequencing information Genome project history}

The organism was selected for sequencing on the basis of its phylogenetic position and 16S rRNA similarity to other members of the genus Enterobacter, and is part of a study of the human digestive flora aiming at isolating all bacterial species within human feces. It was the $10^{\text {th }}$ genome of an Enterobacter species (including genomes from 5 validly published species) and the first genome of E. massiliensis sp. nov. The genome sequence deposited in GenBank under accession number CAE000000000 consists of 224 contigs. Table 2 shows the project information and its association with MIGS version 2.0 compliance [53].

\section{Growth conditions and DNA isolation}

E. massiliensis strain JC163" ${ }^{\mathrm{T}}$ (= CSUR P161 = DSM 26120) was grown aerobically on BHI agar at $37^{\circ} \mathrm{C}$. Four petri dishes were spread and resuspended in $3 \times 100 \mu$ l of G2 buffer. A first mechanical lysis was performed by glass powder on the Fastprep-24 device (Sample Preparation system, MP Biomedicals, USA) during $2 \times 20$ seconds. DNA was then treated with $2.5 \mu \mathrm{g} / \mu \mathrm{L}$ lysozyme $\left(30\right.$ minutes at $\left.37^{\circ} \mathrm{C}\right)$ and extracted through the BioRobot EZ 1 Advanced XL (Qiagen). The DNA was then concentrated and purified on a Qiamp kit (Qiagen). The yield and the concentration was measured by the Quant-it Picogreen kit (Invitrogen) on the Genios_Tecan fluorometer at $118 \mathrm{ng} / \mu \mathrm{l}$. 
Table 2. Project information

\begin{tabular}{lll}
\hline MIGS ID & Property & Term \\
\hline MIGS-31 & Finishing quality & High-quality draft \\
MIGS-28 & Libraries used & Paired-end 3 Kb library \\
MIGS-29 & Sequencing platforms & 454 GS FLX Titanium \\
MIGS-31.2 & Fold coverage & $13 \times$ \\
MIGS-30 & Assemblers & Newbler version 2.5.3 \\
MIGS-32 & Gene calling method & Prodigal \\
& EMBL ID & CAEO00000000 \\
& EMBL Date of Release & November 19, 2012 \\
MIGS-13 & Project relevance & Study of the human gut microbiome \\
\hline
\end{tabular}

\section{Genome sequencing and assembly}

A $3 \mathrm{~kb}$ paired-end sequencing strategy (Roche, Meylan, France) was used. Five $\mu$ g of DNA was mechanically fragmented on the Hydroshear device (Digilab, Holliston, MA, USA) with an enrichment size at $3-4 \mathrm{~kb}$. The DNA fragmentation was visualized using an Agilent 2100 BioAnalyzer on a DNA labchip 7500, with an optimal size of $4.648 \mathrm{~kb}$.The library was constructed according to the 454_Titanium paired end protocol (Roche). Circularization and nebulization were performed and generated a pattern with an optimal at 437 bp. Following PCR amplification through 15 cycles followed by double size selection, the single stranded paired-end library was then quantified on the Quant-it Ribogreen kit (Invitrogen) on the Genios_Tecan fluorometer at $122 \mathrm{pg} / \mu \mathrm{L}$. The library concentration equivalence was calculated as $5.12 \mathrm{E}+08$ molecules/ $\mu \mathrm{L}$. The library was stored at $-20^{\circ} \mathrm{C}$ until use. The library was clonally amplified with $1 \mathrm{cpb}$ in 4 emPCR reactions with the GS Titanium SV emPCR Kit (Lib-L) v2 (Roche). The yield of the emPCR was $14.45 \%$, in the 5 to $20 \%$ range recommended by the Roche procedure.

Approximately 790,000 beads were loaded on $1 / 4$ region of a GS Titanium PicoTiterPlate (PTP Kit $70 \times 75$, Roche) and pyrosequenced with the GS Titanium Sequencing Kit XLR70 and the GS FLX Titanium sequencer (Roche). The run was performed overnight and then analyzed on the cluster through the gsRunBrowser and Newbler assembler (Roche). A total of 283,817 passed filter wells generated $80.8 \mathrm{Mb}$ with a length average of 284 bp. The passed filter sequences were assembled using Newbler with $90 \%$ identity and 40 bp as overlap. The final assembly identified 224 contigs arranged in 11 scaffolds and generated a genome size of $4.92 \mathrm{Mb}$.

\section{Genome annotation}

Open Reading Frames (ORFs) were predicted using Prodigal [54] with default parameters but the predicted ORFs were excluded if they spanned a sequencing gap region. The predicted bacterial protein sequences were searched against the GenBank database [55] and the Clusters of Orthologous Groups (COG) databases using BLASTP. The tRNAScanSE tool [56] was used to find tRNA genes, whereas ribosomal RNAs were found by using RNAmmer [57] and BLASTN against the GenBank database. Signal peptides and numbers of transmembrane helices were predicted using SignalP [58] and TMHMM [59] respectively.

To estimate the mean level of nucleotide sequence similarity at the genome level between $E$. massiliensis strain $\mathrm{JC}^{263^{\mathrm{T}}}$, E. aerogenes strain KCTC 2190 (GenBank accession number CP002824), E. asburiae strain LF7a (CP003026), E. cancerogenus strain ATCC35316 (ABWM00000000), E. cloacae subsp. cloacae strain ATCC13047 (CP001918), E. cloacae subsp. dissolvens strain SDM (CP003678) and E. hormaechei strain ATCC49162 (AFHR00000000), we compared the ORFs only using BLASTN and the following parameters: a query coverage of $>$ $70 \%$ and a minimum nucleotide length of $100 \mathrm{bp}$. 


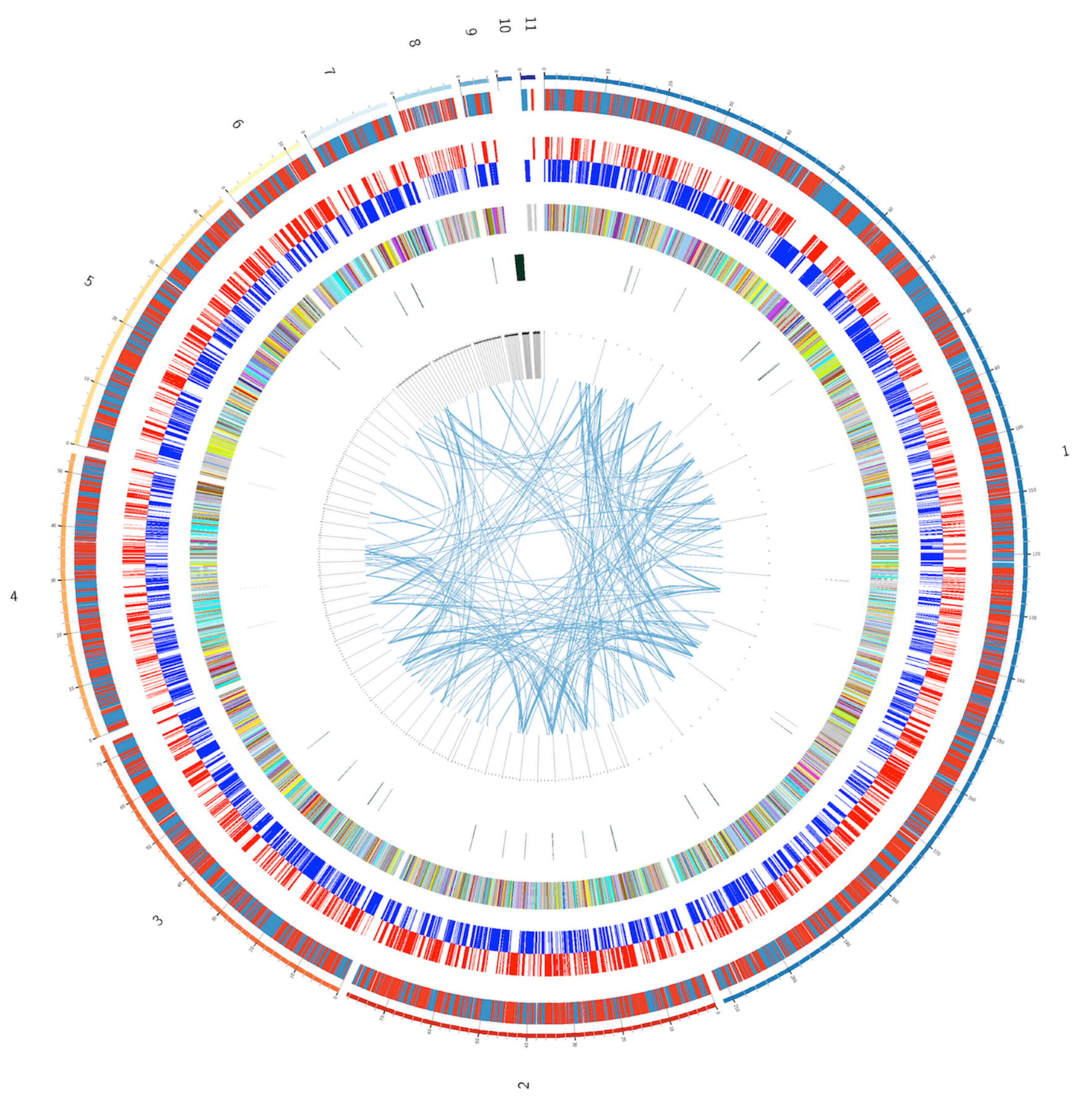

Figure 6. Graphical circular map of the chromosome. From outside to the center: genes on both the forward and reverse strands, genes on forward strand, genes on reverse strand, genes colored by COG categories, RNA genes (tRNAs and rRNAs) and blast of the genome $v s$ itself.

\section{Genome properties}

The genome of E. massiliensis sp. nov. strain JC163 ${ }^{\mathrm{T}}$ is 4,922,247 bp long (1 chromosome but no plasmid) with a $55.1 \% \mathrm{G}+\mathrm{C}$ content (Figure 6 and Table 3). Of the 4,724 predicted genes, 4,644 were protein-coding genes, and 80 were RNAs, including 1 complete rRNA operon, 2 additional $5 \mathrm{~S}$ rRNAs and 75 tRNAs. A total of 3,181 genes
(68.5\%) were assigned a putative function. The remaining genes were annotated as hypothetical or unknown proteins. The distribution of genes into COGs functional categories is presented in Table 4 . The properties and the statistics of the genome are summarized in Tables 3 and 4 . 


\section{Comparison with other Enterobacter species genomes}

Here, we compared the genome of E. massiliensis strain $\mathrm{JC} 163^{\mathrm{T}}$ with those of $E$. aerogenes strain KCTC 2190, E. asburiae strain LF7a, E. cancerogenus strain ATCC35316, E. cloacae subsp. cloacae strain ATCC13047, E. cloacae subsp. dissolvens strain SDM and E. hormaechei strain ATCC49162. The draft genome of E. massiliensis is smaller than those of E. aerogenes, E. cloacae subsp. cloacae and E. cloacae subsp. dissolvens (4.92, 5.28, 5.59 and $4.96 \mathrm{Mb}$, respectively), but larger than those of E. asburiae, E. cancerogenus and $E$. hormaechei $(3.81,4.60$ and 4.80 , respectively). E. massiliensis has a similar $\mathrm{G}+\mathrm{C}$ content to $E$. cloacae subsp. dissolvens (55.1\%) but larger than E. aerogenes, E. asburiae and E. cloacae subsp. cloacae $(54.8,53.8$ and $54.79 \%$, respectively) and lower than E. cancerogenus and E. hormaechei (55.8 and 55.2\%, respectively). E. massiliensis had a greater number of predicted genes than $E$. cancerogenus and E. cloacae subsp. dissolvens $(4,724,4,642$ and 4,646, respectively), but a smaller number than E. aerogenes, E. asburiae, E. cloacae subsp. cloacae and E. hormaechei $(5,021$, $4,805,5,627$ and 4,779, respectively).

In addition, E. massiliensis shared a mean genome sequence similarity of $84.26 \%$ (range 70.05 100\%), $83.89 \%$ (70.03-100\%), 84.36\% (70.05$100 \%), 84.14 \% \quad(70.00-100 \%), 84.14 \%$ (70.05$100 \%)$ and $84.38 \% \quad(70.24-100 \%)$ with $E$. aerogenes, E. asburiae, E. cancerogenus, E. cloacae subsp. cloacae, E. cloacae subsp. dissolvens and E. hormaechei, respectively.

Table 3. Nucleotide content and gene count levels of the genome

\begin{tabular}{lrr}
\hline Attribute & Value & \% of total \\
\hline Genome size (bp) & $4,922,247$ & - \\
DNA coding region (bp) & $4,284,197$ & 87 \\
DNA G+C content (bp) & $2,712,016$ & 55.1 \\
Total genes & 4,724 & 100 \\
RNA genes & 80 & 1.7 \\
Protein-coding genes & 4,644 & 98.3 \\
Genes with function prediction & 3,181 & 68.5 \\
Genes assigned to COGs & 3,710 & 80 \\
Genes with peptide signals & 372 & 8 \\
Genes with transmembrane helices & 702 & 15.1 \\
\hline
\end{tabular}

The total is based on either the size of the genome in base pairs or the total number of protein coding genes in the annotated genome.

Table 4. Number of genes associated with the 25 general COG functional categories

\begin{tabular}{crrl}
\hline Code & Value & \%age & Description \\
\hline J & 175 & 3.77 & Translation \\
A & 1 & 0.02 & RNA processing and modification \\
K & 387 & 8.33 & Transcription \\
L & 169 & 3.64 & Replication, recombination and repair \\
B & 0 & 0 & Chromatin structure and dynamics \\
D & 34 & 0.73 & Cell cycle control, mitosis and meiosis \\
Y & 0 & 0 & Nuclear structure \\
V & 46 & 0.99 & Defense mechanisms \\
T & 176 & 3.79 & Signal transduction mechanisms \\
M & 237 & 5.10 & Cell wall/membrane biogenesis \\
N & 143 & 3.08 & Cell motility \\
Z & 0 & 0 & Cytoskeleton \\
\hline
\end{tabular}


Table 4 (cont.). Number of genes associated with the 25 general COG functional categories

\begin{tabular}{crrl}
\hline Code & Value & \%age & Description \\
\hline W & 0 & 0 & Extracellular structures \\
U & 143 & 3.08 & Intracellular trafficking and secretion \\
O & 138 & 2.97 & Posttranslational modification, protein turnover, chaperones \\
C & 218 & 4.69 & Energy production and conversion \\
G & 472 & 10.16 & Carbohydrate transport and metabolism \\
E & 463 & 9.97 & Amino acid transport and metabolism \\
F & 79 & 1.70 & Nucleotide transport and metabolism \\
H & 175 & 3.77 & Coenzyme transport and metabolism \\
I & 112 & 2.41 & Lipid transport and metabolism \\
P & 305 & 6.57 & Inorganic ion transport and metabolism \\
Q & 99 & 2.13 & Secondary metabolites biosynthesis, transport and catabolism \\
R & 563 & 12.12 & General function prediction only \\
S & 363 & 7.82 & Function unknown \\
- & 934 & 20.11 & Not in COGs \\
\hline
\end{tabular}

The total is based on the total number of protein coding genes in the annotated genome.

\section{Conclusion}

On the basis of phenotypic, phylogenetic and genomic analyses, we formally propose the creation of Enterobacter massiliensis sp. nov. that contains strain JC163 ${ }^{\mathrm{T}}$. This bacterium was cultivated from a healthy Senegalese individual, from whom several other previously undescribed bacterial species were also cultivated through diversification of culture conditions [4-15], thus suggesting that the human fecal flora from humans remains partially unknown.

\section{Description of Enterobacter massiliensis sp. nov.}

Enterobacter massiliensis (mas.il.i.en'sis. L. gen. masc. n. massiliensis, of Massilia, the Latin name of Marseille where strain $\mathrm{JC} 163^{\mathrm{T}}$ was first isolated and cultivated).

Colonies are $2 \mathrm{~mm}$ in diameter on Brain-Heart Infusion agar and are convex, opaque, light-cream colored and circular with regular margins. Cells are rods with tufts of polar flagella and a mean diameter of $1.02 \mu \mathrm{m}$ and a mean length of $1.90 \mu \mathrm{m}$. Optimal growth is achieved in an aerobic

\section{Acknowledgements}

This study was funded by the Mediterranee Infection Fundation. The authors thank Mr Julien Paganini at Xegen Company (www.xegen.fr) for automating the genomic annotation process. atmosphere supplemented with $5 \% \mathrm{CO}_{2}$. Weak growth is observed in microaerophilic conditions. No growth is observed under anaerobic conditions in the absence of $\mathrm{CO}_{2}$. Growth occurs between 25 and $45^{\circ} \mathrm{C}$, with optimal growth occurring between 30 and $37^{\circ} \mathrm{C}$. Cells stain Gram-negative, are nonendospore forming and are motile. Cells are positive for catalase and indole production. $\beta$ galactosidase and glucose, mannitol, sorbitol and rhamnose fermentation activities are present. Nitrate reduction, urease and oxidase activities are absent. Cells are susceptible to ticarcillin, imipenem, trimethoprim/sulfamethoxazole, gentamicin, amikacin, and colimycin, but resistant to fosfomycin and nitrofurantoin. The $\mathrm{G}+\mathrm{C}$ content of the genome is $55.1 \%$. The $16 \mathrm{~S}$ rRNA and genome sequences are deposited in Genbank and EMBL under accession numbers JN657217 and CAE000000000, respectively. The type strain JC163' (= CSUR P161 = DSM 26120) was isolated from the fecal flora of a healthy patient in Senegal. 


\section{References}

1. Lagier JC, Armougom F, Million M, Hugon P, Pagnier I, Robert C, Bittar F, Fournous G, Gimenez G, Maraninchi M, et al. Microbial culturomics: paradigm shift in the human gut microbiome study. [In press]. Clin Microbiol Infect 2012; 18:1185-1193. PubMed

2. Genome Online Database. http://www.genomesonline.org/cgibin/GOLD/index.cgi

3. Tindall BJ, Rossello-Mora R, Busse HJ, Ludwig W, Kampfer P. Notes on the characterization of prokaryote strains for taxonomic purposes. Int I Syst Evol Microbiol 2010; 60:249-266. PubMed http://dx.doi.org/10.1099/ijs.0.016949-0

4. Kokcha S, Mishra AK, Lagier JC, Million M, Leroy Q, Raoult D, Fournier PE. Non contiguousfinished genome sequence and description of $\mathrm{Ba}-$ cillus timonensis sp. nov. Stand Genomic Sci 2012; 6:346-355. PubMed http://dx.doi.org/10.4056/sigs.2776064

5. Lagier JC, El Karkouri K, Nguyen TT, Armougom F, Raoult D, Fournier PE. Non-contiguous finished genome sequence and description of Anaerococcus senegalensis sp. nov. Stand Genomic Sci 2012; 6:116-125. PubMed http://dx.doi.org/10.4056/sigs.2415480

6. Mishra AK, Gimenez G, Lagier JC, Robert C, Raoult D, Fournier PE. Non-contiguous finished genome sequence and description of Alistipes senegalensis sp. nov. Stand Genomic Sci 2012; 6:304-314. http://dx.doi.org/10.4056/sigs.2625821

7. Lagier JC, Armougom F, Mishra AK, Ngyuen TT, Raoult D, Fournier PE. Non-contiguous finished genome sequence and description of Alistipes timonensis sp. nov. Stand Genomic Sci 2012; 6:315-324. PubMed http://dx.doi.org/10.4056/sigs.2685917

8. Mishra AK, Lagier JC, Robert C, Raoult D, Fournier PE. Non-contiguous finished genome sequence and description of Clostridium senegalense sp. nov. Stand Genomic Sci 2012; 6:386-395. PubMed

9. Mishra AK, Lagier JC, Robert C, Raoult D, Fournier PE. Non-contiguous finished genome sequence and description of Peptoniphilus timonensis sp. nov. Stand Genomic Sci 2012; 7:111. http://dx.doi.org/10.4056/sigs.2956294

10. Mishra AK, Lagier JC, Rivet R, Raoult D, Fournier PE. Non-contiguous finished genome sequence and description of Paenibacillus senegalensis sp. nov. Stand Genomic Sci 2012; 7:70-81. http://dx.doi.org/10.4056/sigs.3054650

11. Lagier JC, Gimenez G, Robert C, Raoult D, Fournier PE. Non-contiguous finished genome sequence and description of Herbaspirillum massiliense sp. nov. Stand Genomic Sci 2012; 7:200-209. PubMed http://dx.doi.org/10.4056/sigs.3086474

12. Roux V, El Karkouri K, Lagier JC, Robert C, Raoult $D$. Non-contiguous finished genome sequence and description of Kurthia massiliensis sp. nov. Stand Genomic Sci 2012; 7:221-232. PubMed http://dx.doi.org/10.4056/sigs.3206554

13. Kokcha S, Ramasamy D, Lagier JC, Robert C, Raoult D, Fournier PE. Non-contiguous finished genome sequence and description of Brevibacterium senegalense sp. nov. Stand Genomic Sci 2012; 7:233-245. PubMed http://dx.doi.org/10.4056/sigs.3256677

14. Ramasamy D, Kokcha S, Lagier JC, N'Guyen TT, Raoult D, Fournier PE. Non-contiguous finished genome sequence and description of Aeromicrobium massilense sp. nov. Stand Genomic Sci 2012; 7:246-257. PubMed http://dx.doi.org/10.4056/sigs.3306717

15. Lagier JC, Ramasamy D, Rivet R, Raoult D, Fournier PE. Non-contiguous finished genome sequence and description of Cellulomonas massiliensis sp. nov. Stand Genomic Sci 2012; 7:258-270. PubMed http://dx.doi.org/10.4056/sigs.3316719

16. Hormaeche E, Edwards PR. A proposed genus Enterobacter. Int Bull bacteriol Nomen Taxon 1960; 10:71-74

17. List of Prokaryotic names with Standing in Nomenclature. http://www.bacterio.cict.fr

18. Izard D, Gavini F, Trinel PA, Leclerc H. Deoxyribonucleic acid relatedness between Enterobacter cloacae and Enterobacter amnigenus sp. nov. Int I Syst Bacteriol 1981; 31:35-42. http://dx.doi.org/10.1099/00207713-31-1-35

19. Madhaiyan M, Poonguzhali S, Lee JS, Saravanan VS, Lee KC, Santhanakrishnan P. Enterobacter arachidis sp. nov., a plant-growth-promoting diazotrophic bacterium isolated from rhizosphere soil of groundnut. Int J Syst Evol Microbiol 2010; 60:1559-1564. PubMed http://dx.doi.org/10.1099/ijs.0.013664-0 
20. Brenner DJ, McWhorter AC, Kai A, Steigerwalt AG, Farmer JJ, III. Enterobacter asburiae sp. nov., a new species found in clinical specimens, and reassignment of Erwinia dissolvens and Erwinia nimipressuralis to the genus Enterobacter as Enterobacter dissolvens comb. nov. and Enterobacter nimipressuralis comb. nov. J Clin Microbiol 1986; 23:1114-1120. $\underline{\text { PubMed }}$

21. Dickey RS, Zumoff $\mathrm{CH}$. Emended description of Enterobacter cancerogenus comb. nov. (formerly Erwinia cancerogena). Int J Syst Bacteriol 1988; 38:371-374. http://dx.doi.org/10.1099/0020771338-4-371

22. Hoffmann H, Stindl S, Ludwig W, Stumpf A, Mehlen A, Heesemann J, Monget D, Schleifer KH, Roggenkamp A. Reassignment of Enterobacter dissolvens to Enterobacter cloacae as E. cloacae subspecies dissolvens comb. nov. and emended description of Enterobacter asburiae and Enterobacter kobei. Syst Appl Microbiol 2005; 28:196-205. PubMed http://dx.doi.org/10.1016/j.syapm.2004.12.010

23. Inoue K, Sugiyama K, Kosako Y, Sakazaki R, Yamai S. Enterobacter cowanii sp. nov., a new species of the family Enterobacteriaceae. Curr Microbiol 2000; 41:417-420. PubMed http://dx.doi.org/10.1007/s002840010160

24. Brenner DJ, Richard C, Steigerwalt AG, Asbury MA, Mandel M. Enterobacter gergoviae sp. nov.: a new species of Enterobacteriaceae found in clinical specimens and the environment. Int I Syst Bacteriol 1980; 30:1-6. http://dx.doi.org/10.1099/00207713-30-1-1

25. Stephan R, Van TS, Cleenwerck I, Vancanneyt M, De VP, Lehner A. Enterobacter turicensis sp. nov. and Enterobacter helveticus sp. nov., isolated from fruit powder. Int I Syst Evol Microbiol 2007; 57:820-826. PubMed http://dx.doi.org/10.1099/ijs.0.64650-0

26. O'Hara CM, Steigerwalt AG, Hill BC, Farmer JJ, III, Fanning GR, Brenner DJ. Enterobacter hormaechei, a new species of the family Enterobacteriaceae formerly known as enteric group 75. J Clin Microbiol 1989; 27:2046-2049. PubMed

27. Kosako Y, Tamura K, Sakazaki R, Miki K. Enterobacter kobei sp. nov., a new species of the family Enterobacteriaceae resembling Enterobacter cloacae. Curr Microbiol 1996; 33:261-265. PubMed http://dx.doi.org/10.1007/s002849900110
28. Hoffmann H, Stindl S, Stumpf A, Mehlen A, Monget D, Heesemann J, Schleifer KH, Roggenkamp A. Description of Enterobacter ludwigii sp. nov., a novel Enterobacter species of clinical relevance. Syst Appl Microbiol 2005; 28:206-212. PubMed http://dx.doi.org/10.1016/j.syapm.2004.12.009

29. Zhu B, Lou MM, Xie GL, Wang GF, Zhou Q, Wang F, Fang Y, Su T, Li B, Duan YP.

Enterobacter mori sp. nov., associated with bacterial wilt on Morus alba L. Int I Syst Evol Microbiol 2011; 61:2769-2774. PubMed http://dx.doi.org/10.1099/ijs.0.028613-0

30. Peng G, Zhang W, Luo H, Xie H, Lai W, Tan Z. Enterobacter oryzae sp. nov., a nitrogen-fixing bacterium isolated from the wild rice species Oryza latifolia. Int I Syst Evol Microbiol 2009; 59:1650-1655. PubMed

31. Stephan R, Van TS, Cleenwerck I, Iversen C, Joosten H, De VP, Lehner A. Enterobacter pulveris sp. nov., isolated from fruit powder, infant formula and an infant formula production environment. Int J Syst Evol Microbiol 2008; 58:237-241. PubMed http://dx.doi.org/10.1099/ijs.0.65427-0

32. Chung YR, Brenner DJ, Steirgerwalt AG, Kim BS, Kim HT, Cho KY. Enterobacter pyrinus sp.nov., an organism associated with brown leaf spot disease or pear trees. Int J Syst Bacteriol 1993; 43:157-161. http://dx.doi.org/10.1099/00207713$\underline{43-1-157}$

33. Kämpfer P, Ruppel S, Remus R. Enterobacter radicincitans sp. nov., a plant growth promoting species of the family Enterobacteriaceae. Syst Appl Microbiol 2005; 28:213-221. PubMed http://dx.doi.org/10.1016/j.syapm.2004.12.007

34. Farmer JJ, Asbury MA, Hickman FW, Brenner DJ. Enterobacter sakazakii: a new species of "Enterobacteriaceae" isolated from clinical specimens. Int J Syst Bacteriol 1980; 30:569-584. http://dx.doi.org/10.1099/00207713-30-3-569

35. Manter DK, Hunter WJ, Vivanco JM. Enterobacter soli sp. nov.: a lignin-degrading gammaproteobacteria isolated from soil. Curr Microbiol 2011; 62:1044-1049. PubMed http://dx.doi.org/10.1007/s00284-010-9809-9

36. Mezzatesta ML, Gona F, Stefani S. Enterobacter cloacae complex: clinical impact and emerging antibiotic resistance. [PubMed]. Future Microbiol 2012; 7:887-902. PubMed http://dx.doi.org/10.2217/fmb.12.61

37. Trape JF, Tall A, Diagne N, Ndiath O, Ly AB, Faye J, Dieye-Ba F, Roucher C, Bouganali C, 
Badiane A, et al. Malaria morbidity and pyrethroid resistance after the introduction of insecticide-treated bednets and artemisinin-based combination therapies: a longitudinal study. Lancet Infect Dis 2011; 11:925-932. PubMed http://dx.doi.org/10.1016/S1473-3099(11)70194$\underline{3}$

38. Woese CR, Kandler O, Wheelis ML. Towards a natural system of organisms: proposal for the domains Archaea, Bacteria, and Eukarya. Proc Natl Acad Sci USA 1990; 87:4576-4579. PubMed http://dx.doi.org/10.1073/pnas.87.12.4576

39. Garrity GM, Bell JA, Lilburn T. Phylum XIV. Proteobacteria phyl. nov. In: Garrity GM, Brenner DJ, Krieg NR, Staley JT (eds), Bergey's Manual of Systematic Bacteriology, Second Edition, Volume 2, Part B, Springer, New York, 2005, p. 1.

40. Validation list No. 106. Int I Syst Evol Microbiol 2005; 55:2235-2238.

http://dx.doi.org/10.1099/ijs.0.64108-0

41. Garrity GM, Bell JA, Lilburn T. Class III. Gammaproteobacteria class. nov. In: Brenner DJ, Krieg NR, Staley JT, Garrity GM (eds), Bergey's Manual of Systematic Bacteriology, Second Edition, Volume 2, Springer, New York, 2005 p. 1.

42. Garrity GM, Holt JG. Taxonomic Outline of the Archaea and Bacteria. In: Garrity GM, Boone DR, Castenholz RW (eds), Bergey's Manual of Systematic Bacteriology, Second Edition, Volume 1, Springer, New York, 2001, p. 155-166.

43. Rahn O. New principles for the classification of bacteria. Zentralblatt fur Bakteriologie, Parasitenkunde, Infektionskrankheiten und $\mathrm{Hy}$ giene. Abteilung II 1937; 96:273-286.

44. Skerman VBD, Sneath PHA. Approved list of bacterial names. Int J Syst Bacteriol 1980; 30:225420. http://dx.doi.org/10.1099/00207713-30-1$\underline{225}$

45. Judicial Commission. Conservation of the family name Enterobacteriaceae, of the name of the type genus, and designation of the type species OPINION NO. 15. Int Bull Bacteriol Nomencl Taxon 1958; 8:73-74.

46. Sakazaki R. Genus VII. Enterobacter Hormaeche and Edwards 1960, 72; Nom. cons. Opin. 28, Jud. Comm. 1963, 38. In: Buchanan RE, Gibbons NE (eds), Bergey's Manual of Determinative Bacteriology, Eighth Edition, The Williams and Wilkins Co., Baltimore, 1974, p. 324-325.

47. Judicial Commission. Conservation of the family name Enterobacteriaceae, of the name of the type genus, and designation of the type species OPINION NO. 15. Int Bull Bacteriol Nomencl Taxon 1958; 8:73-74.

48. Editorial Board. OPINION 28 Rejection of the bacterial generic name Cloaca Castellani and Chalmers and acceptance of Enterobacter Hormaeche and Edwards as a bacterial generic name with type species Enterobacter cloacae (Jordan) Hormaeche and Edwards. Int Bull Bacteriol Nomencl Taxon 1963; 13:38.

49. Ashburner M, Ball CA, Blake JA, Botstein D, Butler $\mathrm{H}$, Cherry JM, Davis AP, Dolinski K, Dwight SS, Eppig JT, et al. Gene ontology: tool for the unification of biology. The Gene Ontology Consortium. Nat Genet 2000; 25:25-29. PubMed http://dx.doi.org/10.1038/75556

50. Sillankorva S, Oliveira D, Moura A, Henriques $M$, Faustino A, Nicolau A, Azeredo J. Efficacy of a broad host range lytic bacteriophage against $\mathrm{E}$. coli adhered to urothelium. Curr Microbiol 2011; 62:1128-1132. PubMed http://dx.doi.org/10.1007/s00284-010-9834-8

51. Stackebrandt E, Ebers J. Taxonomic parameters revisited: tarnished gold standards. Microbiol Today 2006; 33:152-155.

52. Seng P, Drancourt M, Gouriet F, La Scola B, Fournier PE, Rolain JM, Raoult D. Ongoing revolution in bacteriology: routine identification of bacteria by matrix-assisted laser desorption ionization time-of-flight mass spectrometry. Clin Infect Dis 2009; 49:543-551. PubMed http://dx.doi.org/10.1086/600885

53. Field D, Garrity G, Gray T, Morrison N, Selengut J, Sterk P, Tatusova T, Thomson N, Allen MJ, Angiuoli SV, et al. The minimum information about a genome sequence (MIGS) specification. Nat Biotechnol 2008; 26:541-547. PubMed http://dx.doi.org/10.1038/nbt1360

54. Prodigal. http://prodigal.ornl.gov

55. GenBank database. http://www.ncbi.nlm.nih.gov/genbank

56. Lowe TM, Eddy SR. tRNAscan-SE: a program for improved detection of transfer RNA genes in genomic sequence. Nucleic Acids Res 1997; 25:955-964. PubMed

57. Lagesen K, Hallin P, Rodland EA, Staerfeldt HH, Rognes T, Ussery DW. RNAmmer: consistent and rapid annotation of ribosomal RNA genes. Nucleic Acids Res 2007; 35:3100-3108. PubMed http://dx.doi.org/10.1093/nar/gkm160 
Enterobacter massiliensis sp. nov.

58. Bendtsen JD, Nielsen H, von Heijne G, Brunak S. Improved prediction of signal peptides: SignalP 3.0. J Mol Biol 2004; 340:783-795. PubMed http://dx.doi.org/10.1016/j.jmb.2004.05.028

59. Krogh A, Larsson B, von Heijne G, Sonnhammer EL. Predicting transmembrane protein topology with a hidden Markov model: application to complete genomes. J Mol Biol 2001; 305:567580. PubMed

http://dx.doi.org/10.1006/jmbi.2000.4315 